\title{
Reliability and validity study of the translated Arabic version of Moorehead-Ardelt Quality of Life Questionnaire II
}

\author{
Saud Aldeghaither, MD, Mohammed Alnaami, MD, FRCSC, Abdullah Aldohayan, MD, Fahad Bamehriz, MD, Sarah Alhaizan, BN, \\ Mohammed Aldeghaither, $M D$, Abdullah Almunifi, $M D$.
}

\begin{abstract}
الأهداف : إنشاء نسخة مترجمة باللغة العربية لاستبيان جودة الحياة المنقح (MA-II)

المنهجية : أجريت ترجمة لاستبيان MA-II إلى العربية بواسطة 3 مترجمين

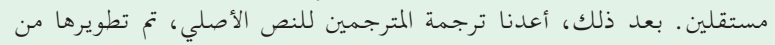

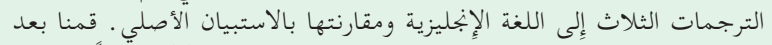

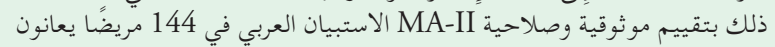

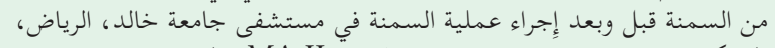

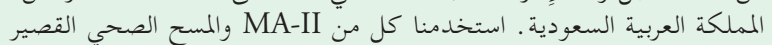

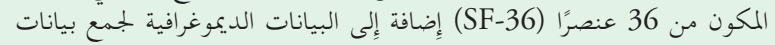

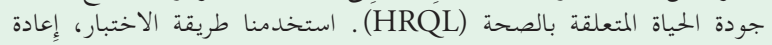
الاختبار وأختبار ألفا كرونباخ لتقييم الموثوقية والاتساق الداخليلي.

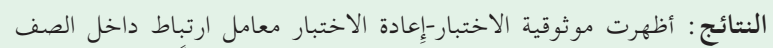

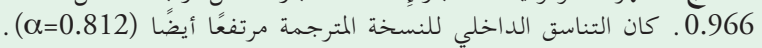

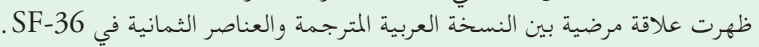

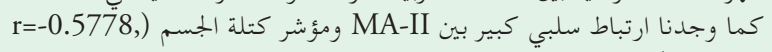
. $(p<0.001$

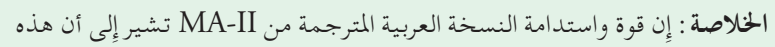

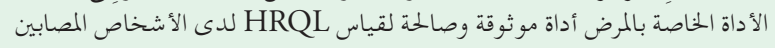
بالسمنة والناطقين باللغة العربية.
\end{abstract}

Objectives: To generate a translated Arabic adaptation of the revised Moorehead-Ardelt Quality of Life Questionnaire II (MA-II), then to assess its reliability and validity.

Methods: The MA-II was translated to Arabic by 3 independent translators. Next, a concise translation, developed from the 3 translations, was re-translated to English and was compared with the original questionnaire. Both the reliability and the validity of the Arabic MA-II were assessed in 144 patients struggling with obesity before and after bariatric procedures at Khalid University Hospital, Riyadh, Saudi Arabia. Apart from the demographic data, both the MA-II and the 36-item short-form health survey (SF-36) were used to collect health-related quality of life (HRQL) data. The test-retest method and Cronbach's alpha $(\alpha)$ were used to assess reliability and internal consistency.
Results: Test-retest reliability exhibited an intraclass correlation coefficient of 0.966 . The internal consistency of the translated version was also high $(\alpha=0.812)$. A satisfactory correlation was demonstrated between the translated Arabic version and the 8 items of the SF36. A significant negative correlation was also observed between the MA-II and body mass index $(\mathrm{r}=-0.5778$, $p<0.001)$.

Conclusion: The robustness and sustainability of the translated Arabic version of the MA-II suggested that this disease-specific instrument is a reliable and valid tool for the measurement of HRQL in obease Arabicspeaking people.

Keywords: obesity, quality of life

Saudi Med J 2022; Vol. 43 (3): 301-306

doi: 10.15537/smj.2022.43.3.20210689

From the Department of Surgery (S. Aldeghaither, Alnaami, aldohayan, Bamehriz, Alhaizan, M. Aldeghaither), Collage of Medicine, King Saud University, from the Department of Surgery (S. Aldeghaither), Prince Mohammed Bin Abdulaziz Hospital, Riyadh, and from the Department of Surgery (Almunifi), Collage of Medicine, Majmaah University, Majmaah, Kingdom of Saudi Arabia.

Received 1st September 2021. Accepted 18th January 2022.

Address correspondence and reprint request to: Dr. Saud Aldeghaither, Department of Surgery, Collage of Medicine, King Saud University, Riyadh, Kingdom of Saudi Arabia.E-mail: saud_k_d@yahoo.com ORCID ID: https://orcid.org/0000-0001-8836-085X

$T$ he prevalence of obesity in Arab countries has increased significantly. According to the World Health Organization (WHO), the highest rate of obesity has been reported in the Gulf countries, such as Kuwait, Saudi Arabia, Bahrain, and United Arab Emirates that are leading worldwide in terms of obesity. ${ }^{1}$ It is interesting to note that the occurrence of obesity is especially pronounced in the female population in these countries, which could be due to traditional or cultural restrictions on the lifestyles of women in 
these countries. ${ }^{2}$ In the Gulf countries, eating habits and a sedentary lifestyle have been major causes of the increased prevalence of obesity. ${ }^{1-3}$

Obesity is perceived as a serious health issue and has been demonstrated to be a risk factor for multiple comorbidities. ${ }^{4}$ Medical illnesses are not the only burden associated with obesity; functional capacity and quality of life (QoL) are also negatively affected by excess body weight. ${ }^{5}$ Weight reduction achieved by bariatric procedures was found to improve patients' subsequent QoL. ${ }^{6}$ Investigators have developed the concept of health-related quality of life (HRQL) to appraise the impact of any medical disease, including obesity, on functional capacity and well-being. ${ }^{7,8}$ Multiple generic and disease-specific questionnaires have been developed to assess HRQL. ${ }^{6}$ Generic instruments are not specific to a single disease; their purpose is to evaluate the effect of any medical illness on the QoL. However, generic questionnaires often lack the sensitivity to detect treatment effects. ${ }^{6}$ The most commonly used generic QoL questionnaire is the 36-item short-form health survey (SF-36). ${ }^{9}$ In contrast, disease-specific HRQL questionnaires were found to be sensitive in detecting minor changes that significantly affect QoL. Furthermore, disease-specific questionnaires were found to be more sensitive than generic questionnaires in detecting treatment effects. ${ }^{6}$

In the last 20 years, multiple obesity-specific HRQL questionnaires have been developed with a focus on measuring the QoL of people suffering from obesity and related problems. ${ }^{6}$ An internationally recognized tool, the Bariatric Analysis and Reporting Outcome System (BAROS), was developed to assess the results of bariatric surgery. The BAROS is a questionnaire that measures broader aspects related to obesity. The BAROS scores depend on the degree of weight loss, alleviation of medical problems, complications associated with bariatric surgery, and the effect of obesity on QoL. ${ }^{10}$ The Moorehead-Ardelt Quality of Life Questionnaire (MA) is one of the oldest and most common questionnaires evaluating the QoL of people struggling with obesity. The MA, which was developed in 1998 as part of BAROS (Edition 2), underwent revision in 2003, yielding the MA-II. ${ }^{11}$ Although the BAROS measures multiple aspects related to obesity, it can be used only after bariatric procedures. In contrast, the MA-II can assess HRQL changes both before and after bariatric

Disclosure. This study was supported by the Saudi Laparoscopic Society, Riyadh, Kingdom of Saudi Arabia. surgery. Thus, MA-II can be used separately or as part of the BAROS. ${ }^{11}$ The MA-II is a user-friendly HRQL questionnaire with a total of 6 questions, which can be completed in less than one minute. The questionnaire also uses illustrations to facilitate the understanding of each question. ${ }^{11}$ Multiple studies have shown that the MA-II has high reliability and high construct validity. ${ }^{12-}$ ${ }_{14}$ The MA-II has been widely used in North America, it has also been translated into multiple European and Asian languages. ${ }^{12-17} \mathrm{Up}$ to our knowledge, there were no published validation studies of an Arabic translation of the MA-II. This study was carried out with the purpose of generating a translated Arabic adaptation of the revised MA-II and then evaluating the reliability and validity of the translated form.

Methods. This is a cross sectional study conducted between January-May 2018. Patients struggling with obesity who visited the bariatric clinic and bariatric educational classes in King Khalid University Hospital, Riyadh, Saudi Arabia, were enrolled for the validation study. The inclusion criterion called for patients who were scheduled for bariatric surgery or had undergone bariatric surgery in the past. If a patient had bariatric surgery in the past 3 months, the patient was excluded from the study, since it was believed that multiple factors other than obesity might influence QoL in the early period after surgery.

A study group consisting of 3 independent bilingual translators was designated to translate the original MA-II questionnaire into the Arabic language, after which their translated versions were validated. Out of the 3 Arabic translations, a concise form was selected based on consensus. The Arabic form was again translated back to the English language by another translator. The study group then carried out a comparison between the re-translated and original English forms of the questionnaire and reviewed their differences. Subsequently, the final Arabic form was generated after linguistic and structural review. A few words needed to be changed due to the religious and cultural background of the Arab population; the group changed the wording of question 5 from "pleasure I get from sex" to "pleasure I get from marital relations." In addition, the meaning of question 6 was lost in translation, and the study group found it necessary to add the word "excessively" to "I live to eat" and "moderately" to "I eat to live".

The Arabic version of the MA-II was similar to the original English version, retaining the same structure and number of questions. Each question was scored on a 10-point Likert scale. The score for each question ranged from $-0.5-0.5$, and the total score for all 6 
questions ranged from $-3-3$. Any question not answered was scored zero. Each item of the questionnaire assessed an aspect related to the QoL: Q1) assessed self-esteem; Q2) physical activity; Q3) social contacts; Q4) the ability to work; Q5) sexuality; and Q6) eating behavior (Figure 1).

Statistical analysis. The test-retest reliability of the MA-II questionnaire was measured using the intraclass correlation coefficient (ICC). The minimum acceptable ICC was 0.75 . The questionnaire was initially answered during a visit to the hospital and later answered again by phone after a 2-3-week interval. This 2-3-week period was believed to be sufficient for the participants to forget their initial answers and for significant clinical changes to occur (Edition 3). The results from the participants involved in the test-retest reliability analysis were not included in the other reliability or validity tests. The reason for this restriction was to eliminate the risk of bias from choosing pre- or post-test answers. Cronbach's alpha $(\alpha)$ was used to assess the internal consistency of the Arabic translation of the MA-II questionnaire. A $\alpha$ of $>0.7$ was considered sufficient. The construct validity of the MA-II, defined by its relation to an existing validated QoL questionnaire, was also assessed. Here, the correlation was evaluated between the results of the MA-II and the Arabic translation of the SF-36. The SF-36 comprises 36 questions, each of which is scored from $0-100$. The survey evaluates 8 QoL domains: physical functioning, physical role limitations, bodily pain, general health, vitality, emotional role limitations, mental health, and social functioning. ${ }^{9}$ The results of these 8 domains were summarized into 2 subcategories: the physical component summary and the mental component summary. The correlation between MA-II and SF-36 scores was studied using Spearman's rank correlation coefficient; values of 0.6 and above were
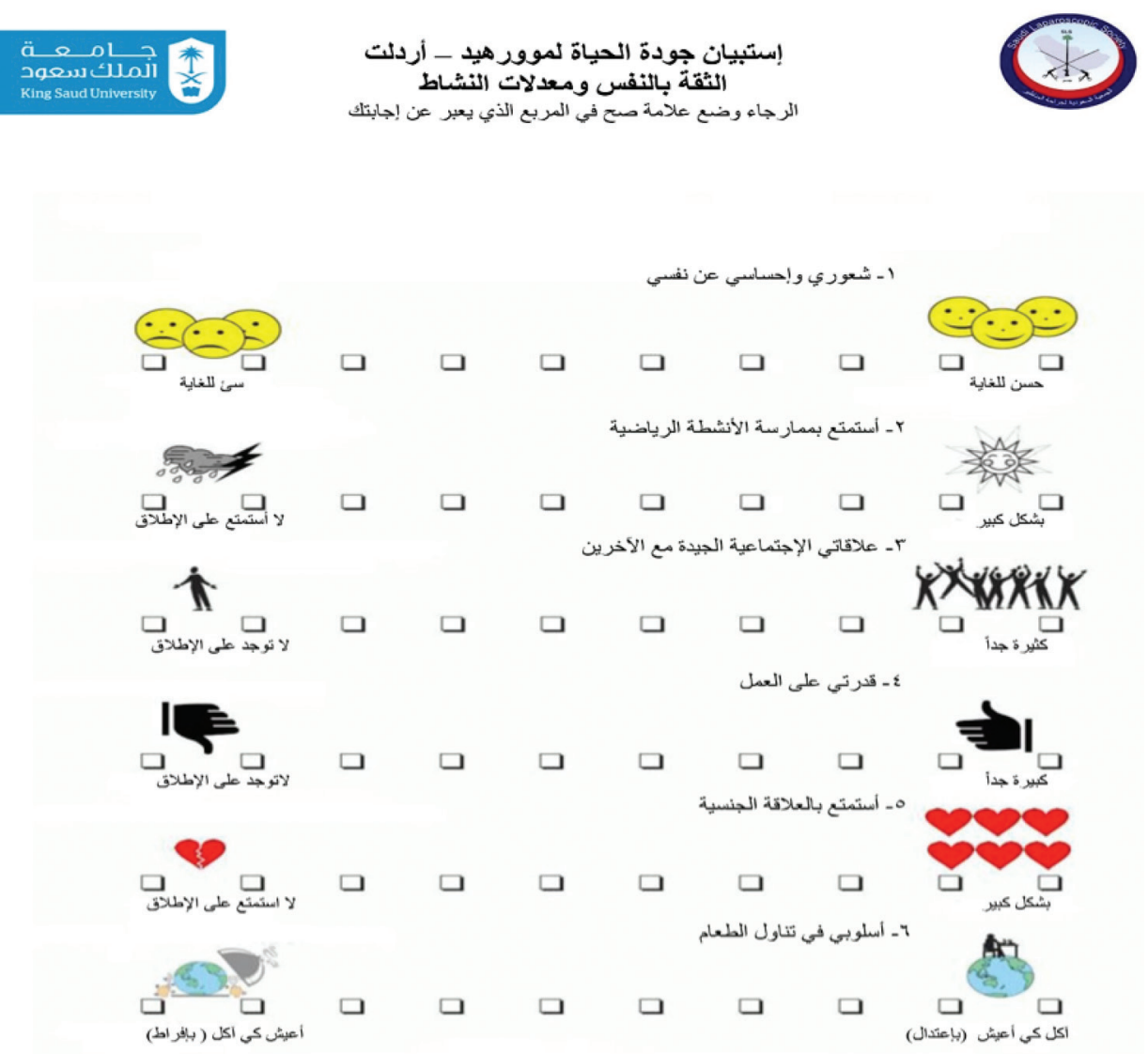

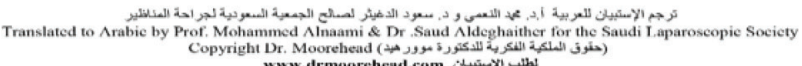

Figure 1 - The Arabic translation of the Moorehead-Ardelt Quality of Life Questionnaire II. 
considered high. The final step was criterion validation, which examines the correlation between scores on a scale and an external non-test criterion. ${ }^{18}$ In this step, the relation between the MA-II scores and the external non-test criterion of body mass index (BMI) was studied using Spearman's rank correlation coefficient. Statistical analysis was carried out using Statistical Package for the Social Sciences for Windows, version 17 (IBM Corp., Armonk, NY, USA)

Results. A total of 104 participants (80 preoperative and 24 post-operative) were enrolled for the reliability and validity studies between January 2017 and May 2017. The demographics and bariatric surgery information of the participants were summarized in Table 1 . The majority of the participants were females $(52.9 \%)$ and few of them did not mention their gender (14.4\%). It was observed that $70.2 \%$ of the participants had a mean BMI between 35-50, and 76.9\% had not undergone any previous bariatric procedures. The majority were educated, with only $10.6 \%$ having less than a high school diploma.

All the questions were answered, except for the question on sexual pleasure, which was not answered by 38 participants. The answers and characteristics of the 40 participants included in the test-retest reliability sample were not included in the rest of the study.

The translated Arabic MA-II questionnaire was found to have a relatively high internal consistency $(\alpha=0.812)$.

The item-total correlation coefficient ranged from 0.39-0.697, with the question on sexual pleasure having the lowest correlation. The question on self-esteem (I usually feel) had the highest correlation, followed by work capability, physical activity, social life, and eating behavior. If any single item was deleted, the alpha coefficient ranged between 0.754-0.817, as shown in Table 2.

The test-retest reliability showed excellent agreement, with an overall ICC: 0.966 (95\% confidence interval (CI): [0.933-0.983]). The ICC values for each question of the MA-II were as follows: general selfesteem, ICC: 0.85 (95\% CI: [0.699-0.925]); physical activity, ICC: 0.882 (95\% CI: [0.764-0.941]); social life, ICC: 0.907 (95\% CI: [0.814-0.953]); work capability, ICC: 0.903 (95\% CI: [0.806-0.952]); sexual life, ICC: 0.962 (95\% CI: [0.925-0.981]); and eating behavior, ICC: 0.812 (95\% CI: [0.623-0.906]).

The concurrent validity of the MA-II was examined through a correlation study with the SF-36. Upon comparison, the correlation between the total MA-II scores and the 8 domains of the SF-36 was found to
Table 1 - Demographics of the study population $(\mathrm{N}=104)$.

\begin{tabular}{lc}
\hline Variables & $\mathbf{n}(\%)$ \\
\hline Gender & \\
Male & $34(32.7)$ \\
Female & $55(52.9)$ \\
Not mentioned & $15(14.4)$ \\
Age (years), mean \pm SD & $32.46 \pm 10.736$ \\
Height $(\mathrm{cm})$, mean \pm SD & $164.25 \pm 11.87$ \\
Weight, mean \pm SD & $113.535 \pm 29.435$ \\
BMI, mean \pm SD & $42.116 \pm 10.60$ \\
$<35$ & $17(16.3)$ \\
$35-50$ & $73(70.2)$ \\
$>50$ & $14(13.5)$ \\
Education levels & \\
Elementary & $5(4.8)$ \\
Intermediate & $6(5.8)$ \\
High school & $29(27.9)$ \\
Diploma & $1(1.0)$ \\
Bachelor & $55(52.9)$ \\
Master & $7(6.7)$ \\
Doctorate & $1(1.0)$ \\
Did you have previous obesity surgery? & \\
Yes & $24(23.1)$ \\
No & $80(76.9)$ \\
\hline & BMI: body mass index, SD: standard deviation \\
\hline
\end{tabular}

Table 2 - The item-total correlation coefficient.

\begin{tabular}{lcc}
\hline MA-II questions & ICC & $\alpha$ if item deleted \\
\hline Usually I feel & 0.697 & 0.754 \\
I enjoy physical activities & 0.670 & 0.759 \\
I have satisfactory social contacts & 0.514 & 0.796 \\
I am able to work & 0.683 & 0.759 \\
The pleasure I get out of marital relations is & 0.390 & 0.817 \\
The way I approach food is & 0.495 & 0.800 \\
\hline MA-II: Moorehead-Ardelt Quality of Life Questionnaire, ICC: item- \\
total correlation coefficient, $\alpha$ : Cronbach's alpha \\
\hline
\end{tabular}

be high with 2 domains of the SF-36 (general health and vitality) and the rest correlations were satisfactory. Correlation of SF-36 with the pre-operative and post-operative groups was found to be satisfactory except for a poor correlation with the role emotional domine in the pre-operative group and a poor correlation with physical functioning in the post-operative group (Table 3).

Upon assessment of the criterion validity, a statistically significant negative correlation was observed between the MA-II scores and BMI $(r=-0.5778$, $p<0.001)$, indicating that patients with higher BMIs have lower MA-II scores.

Discussion. Fortunately, obesity and overweight are preventable. Thus, effective prevention strategies 
can most likely reduce the associated costs and negative health effects. The development of effective behavioral interventions requires an examination of the potential determinants of obesity or weight related behaviors and a review of existing interventions targeting these weight related behaviors. ${ }^{1}$ Therefore, HRQL has been widely used to describe the daily experience of people with health conditions, including obesity.

Defining and measuring the QoL of individuals or a particular population is difficult, as it is influenced by changes in the social and cultural environment, food habits, physical activity, education, and economic factors. ${ }^{2,18}$ An interesting observation regarding the participant demographics was that the majority of them were women. The reason behind this observation could be the lifestyle of women in the Gulf countries. For instance, females have less access to physical activities; the availability of inexpensive labor has reduced the household burden, leading to a sedentary lifestyle; and multiple pregnancies result in weight gain. ${ }^{2}$ The instrument for determining the QoL should therefore be appropriate to the culture and language of the target population. In this study, we focused on obesityassociated effects on the QoL of the Arab population. Hence, an Arabic version of the HRQL tool was the major prerequisite.

A variety of tools are available to gauge the $\mathrm{QoL}$ of patients struggling with obesity. One short and comprehensible tool that can be easily applied is the MA-II. In this study, the MA-II was translated from English to Arabic by 3 independent translators, and the final version was selected by consensus. Interestingly, the high reliability and validity of the English form of the MA-II was replicated to a great extent in this Arabic translation. The translated MA-II had excellent test-retest reliability with high internal consistency.
Per reports in the literature, the lowest Cronbach's $\alpha$ coefficient for an MA-II version was that of the Korean translation $(\alpha=0.76)$, and the highest was that of the German translation $(\alpha=0.88){ }^{14-15}$ In addition, the translated Arabic form of MA-II demonstrated a satisfactory construct validity and a statistically significant criterion validity. A similar result has been observed in all language versions of the MA-II, including Greek, German, Czech, Italian, Spanish, Portuguese, Korean, and Taiwanese. ${ }^{12-17}$

Taking into consideration cultural and linguistic preferences, the question about sexual satisfaction was rephrased to ask about satisfaction with "marital relations." We believed that an eastern religious society would be sensitive to questions concerning their sexual life. Thus, we attempted to rephrase the question with a more culturally acceptable term that would indirectly refer to sexual relations. A total of 38 participants did not answer the question about sexual satisfaction; most of them were unmarried females. We expected this response to be replicated in any study using this Arabic questionnaire, especially if it is used in the Gulf region. With regard to the last question about eating habits, the research team found that the question was not linguistically clear. We decided to add the terms "excessively" and "moderately" to the questionnaire to explain the intention behind the question. Despite this alteration, the participants still faced difficulty in understanding the idea behind this question. However, we were unable to comprehend why participants faced this difficulty. It might be helpful, especially if the questionnaire were distributed in therapy groups, to explain the whole idea of the questionnaire and give a brief explanation of each question before distributing the questionnaire.

Table 3 - Correlation of the MA-II total, pre-operative, and post-operative scores with the SF36.

\begin{tabular}{lccc}
\hline SF36 & MA-II (total patients) & MA-II (postoperative patients) & MA-II (preoperative patients) \\
\hline Vitality & $0.65^{* *}$ & 0.33 & 0.51 \\
Mental health & 0.57 & 0.47 & 0.49 \\
Physical functioning & 0.56 & $0.05^{*}$ & 0.36 \\
Role-physical & 0.55 & 0.47 & 0.37 \\
Role emotional & 0.45 & 0.39 & $0.29^{*}$ \\
Bodily pain & 0.49 & 0.36 & 0.35 \\
Social functioning & 0.54 & 0.38 & 0.49 \\
General health & $0.70^{* *}$ & 0.32 & 0.61 \\
PCS & $0.66^{* *}$ & 0.38 & 0.48 \\
MCS & $0.65^{* *}$ & 0.53 & 0.54 \\
\hline
\end{tabular}

"Poor correlation, "high correlation, MA-II: Moorehead-Ardelt Quality of Life Questionnaire II, SF36: 36-Item Short-Form Health Survey, PCS: physical component summary, MCS: mental component summary 
Study limitations. The small number of post-operative participants included in the validation study, which could be a possible reason for the lower construct validity in this group. This warrants validation of the MA-II in a larger number of bariatric surgery recipients. Another limitation is that its sensitivity to change was not evaluated. Moreover, the consequences of specific types of bariatric procedures were not determined separately. Finally, whereas the other translated forms of the MA-II were validated by comparing their results with at least 2 existing QoL questionnaires, we have compared the Arabic translation to the SF-36 questionnaire only.

In conclusion, the MA-II effectively gauges the QoL of people struggling with obesity, as it is a short, comprehensible, and easily applicable instrument with high response rates. The robustness and sustainability of the Arabic translation of the MA-II suggest that this disease-specific instrument is a reliable and valid tool for the measurement of HRQL in Arabic-speaking people struggling with obesity. We suggest a future reliability and validity study in a larger sample of bariatric surgery recipients.

Acknowledgment. The authors gratefully acknowledge Dr. Basim Abu Rafea for the overall guidance and support. The authors also would like to thank the American Journal Experts and Manuscriptedite.com for English language editing.

\section{References}

1. Balhareth A, Meertens R, Kremers S, Sleddens E. Overweight and obesity among adults in the Gulf States: a systematic literature review of correlates of weight, weight-related behaviours, and interventions. Obes Rev 2019; 20: 763-793.

2. ALNohair S. Obesity in gulf countries. Int J Health Sci (Qassim) 2014; 8: 79-83.

3. Al-Mahroos F, al-Roomi K. Overweight and obesity in the Arabian Peninsula: an overview. J R Soc Promot Health 1999; 119: 251-253.

4. Pantalone KM, Hobbs TM, Chagin KM, Kong SX, Wells BJ, Kattan MW, et al. Prevalence and recognition of obesity and its associated comorbidities: cross-sectional analysis of electronic health record data from a large US integrated health system. BMJ Open 2017; 7: e017583.

5. Kolotkin RL, Meter K, Williams GR. Quality of life and obesity. Obes Rev 2001; 2: 219-229.

6. Fontaine KR, Barofsky I. Obesity and health-related quality of life. Obes Rev 2001; 2: 173-182.
7. Kaplan RM, Bush JW. Health-related quality of life measurement for evaluation research and policy analysis. Health Psychology 1982; 1: 61.

8. Kushner RF, Foster GD. Obesity and quality of life. Nutrition 2000; 16: 947-952.

9. Brazier JE, Harper R, Jones NM, O'Cathain A, Thomas KJ, Usherwood T, et al. Validating the SF-36 health survey questionnaire: new outcome measure for primary care. $B M J$ 1992; 305: 160-164.

10. Oria HE, Moorehead MK. Bariatric analysis and reporting outcome system (BAROS). Obes Surg 1998; 8: 487-499.

11. Moorehead MK, Ardelt-Gattinger E, Lechner H, Oria HE. The validation of the Moorehead-Ardelt Quality of Life Questionnaire II. Obes Surg 2003; 13: 684-692.

12. Maciel J, Infante P, Ribeiro S, Ferreira A, Silva AC, Caravana $\mathrm{J}$, et al. Translation, adaptation and validation of a Portuguese version of the Moorehead-Ardelt Quality of Life Questionnaire II. Obes Surg 2014; 24: 1940-1946.

13. Charalampakis V, Daskalakis M, Bertsias G, Papadakis JA, Melissas J. Validation of the Greek translation of the obesityspecific Moorehead-Ardelt Quality-of-Life Questionnaire II. Obes Surg 2012; 22: 690-696.

14. Sauerland S, Weiner S, Hausler E, Dolezalova K, Angrisani L, Noguera CM, et al. Validity of the Czech, German, Italian, and Spanish version of the Moorehead-Ardelt II questionnaire in patients with morbid obesity. Obes Facts 2009; 2: 57-62.

15. Lee YJ, Song HJ, Heo Y, Oh SH, Kwon JW, Moon KH, et al. Validation of the Korean version Moorehead-Ardelt Quality of Life Questionnaire II. Ann Surg Treat Res 2014; 87: 265-272.

16. Chang CY, Huang CK, Chang YY, Tai CM, Lin JT, Wang JD. Cross-validation of the Taiwan version of the Moorehead-Ardelt Quality of Life Questionnaire II with WHOQOL and SF-36. Obes Surg 2010; 20: 1568-1574.

17. Ates D, Cebeci F. Adaptation and validation of Turkish version of the Moorehead-Ardelt Quality of Life Questionnaire II in bariatric patients. Bariatr Surg Pract Patient Care 2019; 14: 165-171.

18. Cohen RJ, Swerdlik ME, Phillips SM. Psychological testing and assessment: an introduction to tests and measurement (3rd ed.). [Updated 1996; 2021 Oct 25]. Available from: https://psycnet. apa.org/record/1996-97180-000 